for light waves, the refraction effects correspond closely to the standard astronomical effects.

The refractive index of water vapour is greater at radio wave-lengths than at visual wavelengths, and hence appreciable deviations at large zenith angles may be caused by a rapid gradient of refractive index caused by a rapid lapse-rate of water vapour. This problem has been dealt with in the Physical and Meteorological Societies' Report (1947); a quotation from a publication shows the magnitude of the correction that is necessary. The total atmospheric refraction at an elevation of $5^{\circ}$ was ealculated to be $15^{\prime}$, one-third of which was due to water vapour. Irregular ionospheric diffractions occur and are accompanied by changes in the apparent position of the radio star, and this position may vary in a few seconds by $1-2^{\prime}$ of arc on a wave-length of $3.7 \mathrm{~m}$. In addition, regular ionospheric refraction takes place, and the simultaneous reception of radiation from two nearby stars may be responsible for confusion, the resulting error from which is discussed near the end of the paper.

\section{INSTITUTE OF PHYSICS ANNUAL GENERAL MEETING}

$\mathrm{A}^{\mathrm{T}}$

$\mathrm{T}$ the thirty-third annual general meeting of the Institute of Physics, held on May 29 at Bournemouth, during the second Convention of the Institute, the following were elected to take office on October 1: President, Dr. C. Sykes; Vice-President, Prof. F. A. Vick; Hon. Treasurer, Dr. S. Whitehead; Hon. Secretary, Dr. B. P. Dudding; New Ordinary Members of the Board, Mr. A. T. Pickles and Dr. P. S. H. Henry. Prof. A. M. Tyndall, a founder Fellow and pastpresident of the Institute, formerly professor of physics at the University of Bristol, and distinguished for his fundamental work on the mobility of ions and for his services to science and education, was elected to honorary fellowship of the Institute.

The thirty-third annual report of the Board, covering the work of the Institute during 1952, was adopted at the meeting. It records that the Board met six times, and its various standing committees twenty-three times, during the year. The membership increased by 267 to 4,357 ; but there were small decreases in the numbers of subscribers and student members. The total of those elected to grades of membership for which approved academic qualifications in physics are demanded was the highest since the foundation of the Institute. During the year, the first examination for the recently established graduateship grade took place; twenty-one candidates presented themselves and six satisfied the examiners. The annual report refers to the large increase in interest shown both by employers and colleagues in the National Certificates in Applied Physics. Some slight alterations in the regulations governing these Certificates have recently been made by the joint committee of the Ministry of Education and the Institute responsible for the award and control of the courses. In particular, a practical examination need no longer be held as part of the final assessed examination. For the 1952 examinations there were 137 candidates for the Ordinary and 33 for the Higher Certificate.

About half the work of the Institute is now devoted to its publications, and the magnitude and value of this work can be judged by the fact that receipts from sales, including advertisement revenue, were $£ 28,000$ during 1952. The circulation of both the Institute's journals, the Journal of Scientific Instruments and the British Journal of Applied Physics, continues to increase steadily. The amount of material submitted to the journals in 1952 was similar to that in 1951, but the number of special articles and reports in the Journal of Scientific Instruments was rather less than formerly, with more space devoted to original papers. Several new features were introduced into the monthly Bulletin circulated to all members; these include invited articles and an annual index. New volumes published during 1952 in the "Physics in Industry", series were "Industrial Magnetic Testing" by Prof. N. F. Astbury and "Metallurgical Equilibrium Diagrams" by Dr. W. Hume-Rothery, Mr. J. W. Christian and Mr. W. B. Pearson. Another interesting publication, "Physics as a Career", written by Mr. N. Clarke, deputy secretary of the Institute, at the suggestion of the Institute's Education Committee, is a guide to the available avenues of training leading to professional recognition as a physicist. A companion volume is the report, "The Scientific Education of Physicists", issued by the Education Committee. This contains details of the physics departments of all the universities and university colleges of Great Britain and of the technical colleges recognized by the Institute. An additional report entitled "Problems concerning the Education of Physicists" will be published shortly.

The Institute continues to be represented on many joint committees and bodies, including government committees and those of the Royal Society, the City and Guilds of London Institute and the British Standards Institution.

The fourth in the series of "Physics in Industry" conferences, and the first since the Second World War, was held in Glasgow during June 25-28, 1952. Its theme was "Physics in the Transport, Shipbuilding and Engineering Industries", and its object, as of those earlier in the series, was "to promote the application of physics to industry by bringing to the attention of industrial executive engineers and scientists recent developments in applied physics and by providing opportunities for the interchange of ideas with and among professional scientists". The conference was presided over by Sir Andrew McCance, and about four hundred people attended. Sir Andrew MaCance spoke on physics in the service of metallurgy ; Sir Robert Watson-Watt on meteorology in industry ; Prof. A.M. Robb on applications of physics in naval architecture; Mr. M. G. Bennett and Mr. T. A. Eames on applications of physics in transport ; Mr. A. J. Young on automatic control of industrial processes; and Mr. N. Fleming on noise and its suppression. Dr. D. T. N. Williamson gave a public address, with demonstrations, on physics and sound reproduction, and a discussion was held on the education and training of industrial physicists in Scotland. An exhibition of apparatus, instruments and books was held simultaneously at the Royal Technical College, Glasgow, and a catalogue of the exhibition and a handbook of the conference were published. The generous support of the catalogue by the exhibitors resulted in a handsome surplus of close on $£ 1,000$ being added to the Endowment Trust Fund of the Institute.

Details of the various activities of the sixteen local branches and specialist subject groups of the Institute are listed in the report. The Australian Branch held a four-day microscopy conference and exhibition in 
Melbourne; the Manchester and District Branch were responsible for a one-day conference on textile physics; and the Scottish Branch arranged a course of eight lectures at the University of Glasgow on the development of concepts of physical science and a course of seven lectures at the University of Edinburgh on semiconductors. The Education Group held a joint meeting with the Acoustics Group of the Physical Society and a conference on school and university examinations in physics. The summer meeting of the Electronics Group took place at the Clarendon Laboratory, Oxford. The X-ray Analysis Group celebrated the fortieth anniversary of the discovery of X-ray diffraction by a two-day conference in London followed by a dinner at which Prof. M. von Laue was the principal guest, and the Industrial Spectroscopy Group was responsible for the Third International Spectroscopy Colloquium held at High Leigh, Hoddesdon, at which many scientists from overseas were present.

Further repairs and improvements were carried out to the Institute's House at 47 Belgrave Square, London; the Institute is again indebted to Mr. R. S. Whipple for another generous donation, this time of $\mathfrak{£ 0 0}$ to the Furnishing Fund.

\section{CALIFORNIA INSTITUTE OF TECHNOLOGY}

\section{ANNUAL REPORT FOR 195152}

$\mathrm{T}$

HE annual report of the president of the California Institute of Technology for the year ended June 30, 1952 (pp. v +110 ; from the Institute, Pasadena, California, 1953), reflects the current concern in the United States over the shortage of scientific and engineering man-power, though the policy of limiting the freshmen to 180 each year has kept the Institute freer of fluctuations than most other institutions, and there is evidence of a slight increase in enrolments generally which should improve the supply in a few years time. Concern is also expressed lest higher education should depend upon any one source of financial support, particularly upon Federal funds; but the financial report which, together with those of the secretary, the deans and administrative officers, and of the several Divisions, is appended to the president's report, shows that of income and expenditure on organized research totalling nearly 11.5 million dollars, 9.6 millions came from the Federal Government for the Jet Propulsion Laboratory, the South Californian Co-operative Wind Tunnel, and the Vista Project, while a further 1.3 millions was received and spent on other research contracts. Gifts for current operations, however, exceeded $1 \cdot 2$ million dollars, and the president points out that, except for the few projects in such fields as nuclear physics and aeronautics, the educational and research work of the Institute is still mainly supported by private funds.

Among the features of the research during the year is the new technique developed in the Division of Biology by Prof. R. Dulbecco for studying those viruses which attack animal tissue, as compared with those which attack only plants or bacteria. The new synchrotron which has been under construction during the past two years has produced electrons with an energy of $525 \mathrm{MeV}$., and this beam causes the creation of $\pi$-mesons. Active study during the past year of the new unstable sub-atomic particles which occur in the cosmic rays has led to the identification of at least five different types of such particles. In the Division of Chemistry and Chemical Engineering the structure of complex molecules is being determined by the electron-diffraction method and by infra-red spectroscopy. Evidence was obtained during the year that a polypeptide helix without $3 \cdot 6$ amino-acid residues per turn is present not only in some synthetic polypeptides but also in proteins like hair, finger-nail, skin, hæmoglobin and serum albumin. The sequence of amino-acids in proteins continued to be studied by chromatographic analysis, and the emphasis in work in chemical engineering is being gradually changed from the study of the equilibrium thermodynamic properties of fluids at high pressures to that of nonequilibrium phenomena, such as thermal and material transfer, under quiescent and convective conditions.

In the Division of Civil, Electrical and Mechanical Engineering and Aeronautics, application of the Institute's electric analogue computor has led, by means of new electric circuit analogies, to the development of a rapid and general method for the static stress analysis of complex structures. A new research programme on the basic insulation characteristics of rotating machine insulation was started; and a new technique developed for use in the high-speed water tunnel permits the determination of the dynamic force coefficients of submerged bodies. Advances were made in two long-range programmes concerned with turbulence and compressible fluid flow, and in the Division of the Geological Sciences, where earthquake records have been studied for more than twenty years, the recent Tehachapi earthquake and its many after-shocks were fully recorded on a dozen instruments in the Pasadena Laboratory and in several field stations. The shock also focused fresh attention on building design for seismically active regions, and the Division of Engineering is engaged in designing structures having maximum resistance and in predicting the behaviour of a given structure.

\section{ENZYMATIC AND CHEMICAL OXIDATION OF DIMETHYL- PHOSPHORAMIDES TO BIOLOGICALLY ACTIVE DIMETHYL- PHOSPHORAMIDE OXIDES}

\section{By J. E. CASIDA, T. C. ALLEN and M. A. STAHMANN}

Departments of Biochemistry and Entomology, University of Wisconsin, Madison

CEVERAL dimethylphosphoramides have been $S$ investigated as insecticides, and the group as a whole shows great promise in protecting plants against insect pests by chemotherapeutic action. One of these chemicals, octamethylpyrophosphoramide or 'Schradan', has been developed commercially as a systemic insecticide. These alkylamino phosphates differ from the related toxic alkyl phosphates in that they are generally poor in vitro inhibitors of cholinesterase, but nevertheless animals exposed to $2-50 \mathrm{mgm}$. $/ \mathrm{kgm}$. show typical symptoms of acetylcholine accumulation ${ }^{1-4}$. Furthermore, these alkylamino phosphates produce a differential in vivo inhibition of the peripheral cholinesterase ${ }^{1,8}$. They are relatively ineffective inhibitors of chymotrypsin ${ }^{6}$. 